Evaluation of SCC Test Methods for

Inconel 600 in Low Temperature

BNL-NUREG-32798

\title{
Aqueous Solutions
}

R. C. Newman, R. Roberge* and R. Bandy

BNL-NUREG--32798

Corrosion Science Group

DE83 011358

Department of Nucleer Energy

Brookhaven National Laboratory

Upton, New York 11973

*Visiting Scientiot. Permanent Addreas: Institut de recherche d'Hydro-Québec, Varennes, Québec, Canads

\author{
Paper submitted for publication in ASTM proceedings \\ "Environment-Sensitive Fracture: Evaluation Comparioon \\ of Test Methods"
}

Symposium held at Nationsl Bureau of Standards,

April 1982

\section{DISCLAIMER}

\begin{abstract}
This report was prepared as an account of work sponsored by an agency of the Unitod States Government. Neither the United States Government nor any asency thereof, nor any of their employees, makes any warranty, express or implied, or assumes any legal liability or responsibility for the accuracy, completenes, or usefulness of any information, apparatus, product, or process discloed, or represents that its use whuld not infringe privately owned rights. Reference herein to any specific commercial product, prooese, or service by trade name, trademark, manufacturer, or otherwive does not necesurily conatitute or imply its endorsement, recommendation, or favoring by the United States Government or any aseacy thereof. The vieme and opinions of authors expresed herein do not necesanily state or reflect those of the United States Government or any asency theroof.
\end{abstract}

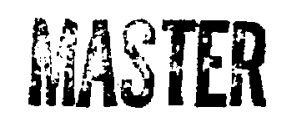


Key worda: corrosion, atrens-corronion cracking, nickel alloy, sensitiration, stean generator corroaion, slow atrain rate teating. 


\title{
Eveluation of SCC Tent Methode for Inconel 600
}

\section{in Low Temperature Aqueque Solutions}

\author{
R. C. Newman, R. Roberge and R. Bandy \\ Corrosion Science Group \\ Department of Nuclear Energy \\ Brookhaven National Laboratory \\ Upton, New York 11973
}

\section{Abstract}

In late 1981, widespread leakage was encountered in Alloy 600 steam generator tubing at the Three Mile Island Onit 1 nuclear power plant. The phenomenon was identified as low temperature intergranular treas-corrosion cracking (SCC) initiated from the inner surfaces of the tubes exposed to the primary coolant. A testing program was initiated to examine the material and environmental factors relevant to these failures, which were found to be associated with sensitization of the material and contamination of the coolant by air and sodium thiosulfate. The test solutions contained 1.37 boric acid with various additions of sulfur compounds and lithium hydroxide. Constant extension rate testing was used as the primary tool to examine environmental effects such as the inhibition of cracking by lithium hydroxide. Important effects of crack initiation frequency on the specimen potential (and therefore crack velocity) are demonstrated. In some of these tests, straining was interrupted following crack initiation and the effects of further environmental additions monitored by following the load decay at constant total strain. This procedure generally resulted in a different ranking of the environments. O-bend tests showed that the ranking of different sulfurcontaining environments was also highly dependent on the metal heat treatment. 
Introduction

Stress-corrosion cracking of Alloy 600 at temperatures below $100^{\circ} \mathrm{C}$ was largely a laboratory phenomenon until 1981, when nultiple tube penetration by circunferential cracke occurred in the stean generators of a non-operating preasurized water reactor. [1]. Several thousend cracke hed grown to at least $0.5 \mathrm{wm}$ depth, of which a high proportion had arrested after progressing 80-907 through the tube walls. Contamination of the borated primary coolant by sodium thiosulfate seems to have been the principal environmental factor involved. In addition, sulfur-rich deposits in the tubes may indicate an important role of earlier thiosulfate intrusion during high temperature operation, and could themselves give rise to metastable dissolved species by reaction with air and water. The chemical state of the sulfur in the aqueous phase at the time of cracking is not known with certainty; however it may be safely assumed that a metastable form auch as thiosulfate or tetrathionate was present. The aqueous concentration of sulfur was probably around 0.7 ppm, equivalent to $1.1 \times 10^{-5} \mathrm{M} \mathrm{Na}_{2} \mathrm{~s}_{2} \mathrm{O}_{3}$. The tubing was sensitized by its stres relief treatment following fabrication of the steam generators, and was subject to longitudinal stresses. During temperature excursions in the period preceding obvious tube damae, these stresses may have varied in a manner conducive to SCC initiation. However, knowledge of the tine at which air first intruded is also critical. In this investigation we have used several test techniques to examine the sulfur-induced scc of sensitized Inconel 600 , at temperatures from 22 to $95^{\circ} \mathrm{C}$. Details of the influence of environmental and metallurgical variables are given in two further papera. [2,3]

\section{Testing philosophy}

In this work the constant extension rate (CER) test was used to rank various dilute environments as rapidly as possible, using a constant netallurgical condition. In order to distinguish between genuine enviromental effects and artifacts peculiar to the CrR test, an interrupted 
teet was also used. Straining was halted following obvious crack initiation, and additions were made to the environment while following the load relaxation due to crack propagation. In this fashion it was possible to establish the envirunmental alterations necessary to arrest a constant number of propagating cracks at moderate stress intensities. These critical inhibitive solution compositione are coneervative in the sense that, if a propagating crack is arrested, no uncertainty exists as to the effectiveness of the inhibition on crack initiation. Examples are given where the CER test predicted immunity but the load relaxation test showed continued crack propagation.

When CER testing is used to predict or explain service failures, it is often criticized as being too severe. However, the paucity of information on SCC initiation mechanisms at smooth surfaces renders this a dangerous attitude. Many alloy carry films of reaction products developed over years of service, which are not easy to reproduce in the laboratory; these may facilitate SCC initiation in various ways during static loading [4]. In a recent study of the low temperature SCC of sensitized stainless uteels, the effects of low levels of chloride ions were found to depend critically on the surface condition, even in CER tests [5]. Here we have compared results from static tests with the CER data, and have attempted to account for the observed differences in crack initiation behavior. In particular, the different effects of thiosulfate and tetrathionate on crack initiation are highlighted: this may be considered an important aspect of test methodology when SCC is known to have occurred as a result of an unknown combination of metastable sulfur compounds.

\section{EXPERIHENTAL PROCEDORE}

Material

Alloy 600 tubing, outside dir...er $22.2 \mathrm{~mm}$ and wall thickness $1.24 \mathrm{~mm}$, was obtained from Huntington Alloys (beat 9751). It had received a mill anneal and had the composition given in Table 1. The yield atrength and 
elongation to failure vere about $310 \mathrm{MPa}$ and $40 \%$, respectively. 76 lengths of tube vere cut and machined so that two curved tensile apecimens could be obtained from each length by slitting lengthwise. The gauge length and width were $12.7 \mathrm{~mm}$ and $2.54 \mathrm{mectively.} \mathrm{In} \mathrm{addition,} \mathrm{hemicylindrical} \mathrm{tube}$ sections were cut for use as D-bend secimens. For CRR testing the tensile specimens were either sensitized directly at $621^{\circ} \mathrm{C}$ for $18 \mathrm{~h}$ or solution annealed at $1135^{\circ} \mathrm{C}$ for $45 \mathrm{~min}$. before sensitization at $621^{\circ} \mathrm{C}$ for $18 \mathrm{~h}$. The latter treatment gave a yield strength of about $210 \mathrm{MPa}$ and an elongation to failure of about 54\%. The aensitization heat treatment approximates to the strese relief treatment of the ateam generator where the service failures occurred; when applied directly to the mill annenled material it did not affect the mechanical properties. U-bend testa were mainly carried out on directly sensitized material, with a few teats on samples which had been solution annealed prior to sensitization. The concave face of the tube was on the outside of the bend in every case, giving very severe stresses and a gradation in atrese state.

\section{Testing Environments}

For CER testing in dilute thiosulfate solutions, the test environments were based on a $1.37(0.21 \mathrm{M})$ boric acid solution prepared from deionized water (conductivity < $0.1 \mu \mathrm{S}$ ) and an analyzed grade of boric acid. The latter contained < $3 \mathrm{ppa} \mathrm{Cl} \mathrm{(giving} \mathrm{<} 39 \mathrm{ppb} \mathrm{C1-} \mathrm{in} \mathrm{a} 1.32$ solution), < 1.6 ppm P as $\mathrm{PO}_{4}{ }^{3-}$ (giving $<21 \mathrm{Ppb} \mathrm{P}$ ) and $<10 \mathrm{ppm} \mathrm{S}$ as $\mathrm{SO}_{4}{ }^{2-}$ (giving < 130 $\mathrm{ppb} S$ or $4 \times 10^{-6} \mathrm{M} \mathrm{SO}^{2-}$ ). Naturally these elements could be present in an insoluble form, giving even lower dissolved concentrations. Typically the 1.37 solution had a conductivity of $9.5 \mu \mathrm{s}$ at $25^{\circ} \mathrm{C}$, with a $\mathrm{pH}$ close to 4.8. Lithium hydroxide, sodium thiosulfate and sodium tetrathionate were the other reagents used. 
Constant Extension Rate Testing

The CER specimens, abraded to a 600 grit finish, were utrcined at a nominal rate of $3 \times 10^{-6} \cdot-1$ using zirconia coated steel pins to tranamit the load. About $0.3 \mathrm{~mm}$ of anomalous extension occurred in every teat owing to lack of rigidity. In tests where the potential was monitored or controlled, an Inconel 600 wire was spotwelded to one end of the apecimen as an electrical connection. A saturated calomel electrode (SCE) was placed inside " quartz tube with a capillary at one end plugged with glase wool, then immersed directly in the colution. This double diffusion barrier effectively prevented chloride contamination of the test solution. The solution was airsaturated and contained in a 3 liter beaker around the specimen assembly, with a Teflon 1id. Temperature control was accompliahed using a thermostatically controlled infra-red 1amp. For tests where additions wexe made to the environment after crack initiation, a magnetic etirrer was used to ensure rapid homogenization. Stirring at low rates did not eignificantly affect crack growth. For interrupted teats, the machine was switched off and the decay of the load due to SCC monitored on a chart recorder. Changes in crack velocity due to environmental alterations were evidenced by changes in the rate of load decay. In one test, a crack was introduced at constant deflection by straining in a $0.1 \mathrm{M}$ thiosulfate solution, then locking the machine. The test container was then flushed with progressively more dilute solutions until it contained 0.7 ppm sulfur as Na2s203. The load decay was examined for evidence of continuing crack propagation; the effects of further additions of boric acid and lithium hydroxide were also investigated.

D-bend Testing

A wide variety of environments was used to test both solution annealed/sensitized (SAS) and mill annealed/sensitized (MAS) material. Most of the results will be reported in another paper [3]. Here only one set of tests is described: the evaluation of the relative effects of thiosulfate and tetrathionate on SCC susceptibility of MAS and SAS material. 
RESULTS AND DISCUSSION

Microstructure of Material

It is worthwhile to review-come-of the -factors influencing-the sensitization of Inconel 600. Figure la showe the microstructure of the MuS material. This etch preferentially attacka carbides. Heavy grain boundary precipitation is accompanied by two types of intragranular carbides. Some are distributed rather randomly, while others are lined up along "ghost" grain boundaries. The latter are remnants of the structure prior to the mill anneal - indeed, the differences between the mill annealed structure (immune to SCC) and the MS structure were very minor when examined at this resolution, so that the phosphoric acid etch is not a reliable indicator of sensitization in this material. The consequence of the limited carbon dissolution during the mill anneal is that the amount of carbon available for sensitization may be rather small (say, 0.017 ) even in a 0.047 carbon material. Taken in conjunction with the variability in carbon content and mill anneal condition. of production tubing, these considerations rendered it necessary to use a solution anneal prior to sensitization in order to eramine the environmental varables in SCC. The microstructure of the SAS material is shown in Figure 1b, and represents classical severe sensitization where almost the full $0.04 \mathrm{~T}$ C was available in solid solution. In another paper (3) the results of electrochemical potentiokinetic reactivation (EPR) testing will be reported; when applied to MAS and SAS material this technique gave a good indication of the relative degree of sensitization. The charge densities per unit grain boundary area passed during reactivation of mill annealed, MAS and SAS material were 111, 209 and $774 \mathrm{C} \mathrm{cm}^{-2}$ respectively. The electrolyte was $0.01 \mathrm{HCWS}+0.5 \mathrm{M} \mathrm{H}_{2} \mathrm{SO}_{4}$ at roon temperature, the passivation treatment $400 \mathrm{mV}$ (SCE) for 4 minutes and the reverse $8 \mathrm{can}$ rate $1 \mathrm{mV} / \mathrm{s}$. 


\section{GER Testing}

Preliminary teste on the MS material using non-borated sodium thiosulfate solutions at $40^{\circ} \mathrm{C}$ showed that no scC could be induced below $70 \mathrm{ppm}$ s (1.1 $\times 10^{-3}$ H Na2s203). In a $0.1 \mathrm{M}$ solution cracking was rapid, with $0.7 \mathrm{~mm}$ crack growth in $24 \mathrm{~h}$. Since these tests clearly offered no possibility of accounting for the steam generator failures, which occurred at much more dilute levels of sulfur, they were continued using SAs material. Here, with $1.37 \mathrm{H}_{3} \mathrm{BO}_{3}$, SCC occurred at concentrations as low as $75 \mathrm{ppb}$ sulfur ( $\left.1.2 \times 10^{-6} \mathrm{M} \mathrm{Na}_{2} \mathrm{~S}_{2} \mathrm{O}_{3}\right)$ and at high rates. The rate increased with temperature up to at least $80^{\circ} \mathrm{C}$. All these results are discussed in detail elsewhere [2]. At $0.7 \mathrm{ppm}$ oulfur the effects of thiosulfate and tetrathionate were cumparable.

The influence of teat procedure was revealed most clearly in tests where the effect of lithium hydroxide additions was studied. Although sufficient LiOH additions alwaye inhibited SCC at a fixed sulfur level, an apparent increase in SCC susceptibility with Li concentration was observed in the range just below the critical inhibitory value. This effect is sown in Figure 2, for two SCC susceptibility indices, and was at first puzzling as the scC process was thought to be influenced sirongly by anion electromigration into the cracks. Additions of LiOH cause a proportional degree of ionization of the boric acid, giving $\mathrm{HB}_{4} \mathrm{O}_{7}^{-}$ions which carry current in competition with the thiosulfate lons and therefore restrict the thiosulfate enrichment which can be attained in a crack. One therefore anticlpates that the ratio of inhibiting $\left(\mathrm{HB}_{4} \mathrm{O}_{7}\right)$ to aggressive $\left(\mathrm{S}_{2} \mathrm{O}_{3}{ }^{2-}\right)$ Ion concentrations will be more important than the absolute $\mathrm{HB}_{4} \mathrm{O}_{7}$ - concentration (1.e. the $\mathrm{pH}$ ) in determining how much LIOH must be added to prevent SCC. A continuous decrease in SCC velocity with LiOH concentration is expected, other things being equal.

The effects of lithium hydroxide additions on propagating cracks were examined by interrupting a CER test and following the load decay with periodic LiOH additione (Figure 3). Here $5.6 \mathrm{ppm}$ lithium again sufficed to lower the crack growth rate to an extremely low value at $0.7 \mathrm{ppm}$ sulfur. Now, however, the cracking rate decreased smoothly with lithiu concentration. For 7 Ppa 
sulfur approximately $150 \mathrm{ppm}$ LI were requixed to Inhibit SCC, and again the progression in rate was mooth. Again the most dramatic change in crack velocity occurred between LI/S ratios of 3 and B. At low LI concentrations the cracking rate with $0.7 \mathrm{ppa}$ oulfur was, surpriaingly, higher than in CER tests (F1gure 2). At the end of this test, examination of the specimen showed one deep, planar crack with several minor secondary cracke which could not have affected the load relaxation significantly. These results confirm the general expectations of the model based on electrotransport of aggreseive and Inhibiting anions.

It is notable how rapidly the environmental changes affected the cracking rate in the teat shown in Figure 3. The notion that a stress-corrosion crack tip is isolated from the bulk environment is clearly wrong in this case. By including alectrical forces in the analysis of mase transport in the cracks, the rapidity of the effect can be explained. For seneitized Type 304 stainless steel in non-borated thiosulfate solutious, the arresting of SCC by sulfate additions [6] is even more rapid owing to the higher crack velocity and consequently large potential gradient driving the sulfate ions into the crack and parmitting a net diffusion of thiosulfate away fron the crack tip.

The key to understanding the apparently conflicting results of Figure $\lambda$ lies in the influence of crack initiation frequency on some uncontrolled parameters in the CER test. As Figure 2 shows, additions of lithium hydroxide up to $2.8 \mathrm{PP} \mathrm{Li}$ drastically reduce the number of cracks initiated during scC. One effect of the reduced number of cracks could be to raise the crack tip strain rate compared with a multiple cracked specimen, thereby enhancing SCC. However, our interrupted CER tests in this system have shown rather little influence of stress on the crack growth rate, suggesting that the cracks are easily brought to their maximun velocity. This indicates a low apparent threshold stress intensity for SCC and a correspondingly low stress intensity at which the stage II (constant crack velocity) regine is reached. We therefore favor an electrochemical interpretation in which scc propagation by anodic dissolution is the aerated solution generates a polarizing current which is proportional to the sumed products of crack tip length and crack velocity. This current flows to the external specinen surface and depresses 
the average potential of the apecimen in an upan circuit test. Depenoing on the injedance of the surface and the solution conductivity, the current flow may be more or less localized to the region around the crack. Since the crack velocity in dilute environments of this type increases with more positive potential over a large range [7], a specinen with many cracks will crack at a slower rate than one with one crack, other things being equal.

A typical potential veraus atrain trace for a CER test is shown in Figure 4. Initiation of SCC is characterized by a gradual ahift of potential in the negative direction, which eventually stabilizes when a constant polarizing current is being generated by a fixed number of cracks moving at a constant rate. For this particular test, this regime occupies nearly half the total test duration. When final fracture occurs, the polarizing current from the cracks ceases and the potential rapidly returns to its value before crack initiation. In tests with many cracks, potentials as low as $-300 \mathrm{mV}$ (SCE) are obtained in lithium-free solutions and the cracking rate is restricted. In tests with only one crack of significant length, such as the interrupted CER test described earlier, the potential remains close to $-100 \mathrm{mV}$ and the cracking is much more rapid whether or not cont" wous straining is applied. Indeed, since further straining tends to initiste new cracks, the subsequent rate of cracking is more rapid in the interrupted (conetant deflection) test than in the continuing CSR test. The effect is particularly apparent in this material, as the currents emerging frov cracks in sensitized alloys tend to be larger than in more homogeneous materials $[6,8]$.

One might consider that the above effects could easily be eliminated by controlling the potential, and are therefore trivial. However, the solutions involved in these tasts have very low conductivity and similar effects may operate in even more poorly conducting systems. Atiempts to control the potential in very dilute solutions ma create additional probless.

In Figure 5, the results shown in Figures 2 and 3 are constructed schemetically, showing why the different test methods give different results. 
The maximus crack velocities are dravn as varying linearly with potential, defining an obnic resiatence which is associated with the solution ineide a crack; in practice, this varies in a very complex fashion because a faster moving crack attracte a more conducting solution. These coneiderations are discused elsewhere-in more-detail-[2]. For-a fixed number of identical cracke there is a shift in potential depending on crack velocity, independent of the larger shift associated with differences in crack initiation frequency.

\section{Correlation of Static and Dynamic Teets}

In the preceding section it has been denonetrated that an initiated crack in SAS material can propagate vith eace in environmente representing the contaminated reactor vater. However, even in CER teste initiation effects were important. In order to attempt a full description of the eervice phencienon, it was necessary to study the initiation of SCC using U-bend specimens. All these tests were perforned without removing the visible oxide filn from the sensitizing heat treatment in air; thus the act of making the $\mathbb{U}$ bend produces cracks in the film which should favor crack initiation. Sinilar flawe were probably present in the more complex surface film on the Inconel stean generator tubes, owing to high peak scresses during cooldown from high temperature.

In neutral solutions containing $0.1 \mathrm{M} \mathrm{Na2S}_{2} \mathrm{O}_{3}$ and at temperatures of $22,40,60$ and $80^{\circ} \mathrm{C}$, no SCC occurred in Mas $\mathrm{D}$-bends for a tesc time of 2 weeke. This was not an especially surprising result, although the contrast with the $0.7 \mathrm{~m} /$ day cracking rate in CER tests at $22^{\circ} \mathrm{C}$ is notable. In order to initsate SCC in $0.1 \mathrm{M}$ thiosulfate solutions at $22^{\circ} \mathrm{C}$, it was necessary to bring the PH to 3-3.5 with sulfuric acid. Initiation occurred within a few hours, and the crack propagation rate was comparable with those measured in the CSR tests. In another paper [6] it has been argued that the crack tip $\mathrm{PH}$ durins thiosulfate SCC is close to 3; thus, in the acidified solution, the earliest stages of cracking are not hindered by the necessity for localized pH 
changes. Farallel experimente with polished surfaces showed that the acidified thiosulfate solution caused a aild generalized intergranular attack in addition to the rapid scC.

As supplied by most manufacturers, comercially pure sodiun tetrathionate gives a $\mathrm{pH}$ of 3.5 - 4.0 for a $0.1 \mathrm{H}$ solution. This promotes very rapid SCC initiation and renders it an excellent test reagent for sensitization in both stainless steels and nickel alloys. This has been pointed out by Berge and Donati [9]. For the MAS D-bends, cracks were already visible after 1 hour immersion in aerated $0.1 \mathrm{~K} \mathrm{Na}_{2} \mathrm{~S}_{4} \mathrm{O}_{6}$ at $22^{\circ} \mathrm{C}$. Further experiment: with more dilute solutions howed that the tetrathionate could induce scC of MS U-bends in 4 days at a concentration $\left(10^{-}-4 M\right)$ where thiosulfate was inactive even in CER tests. This is neither a pH nor a potential effect, but shows there are subtle differences between the metatable sulfur compounds in their ability to promote sCC initiation at smooth surfaces. In CER tests of sensitized stainless steels [10] or SAS Inconel 600 [2] thiosulfate causes SCC at lower concentrations than tetrathionate. For the $0.1 \mathrm{M}$ tetrathionate colution, deoxygenation to $<0.1 \mathrm{ppm}$ by a nitrogen purge caused a drop in potential and a reduction in crack propagation rate by a factor of at leat ten but did not eliminate SCC altogetber. However, the result showe that the oxidixing power of tetrathionate is not the only factor determining the potential and crack propagation rate, as implied by Cowan and Gordon [11].

U-bend tests of SAS material produced cracking at aqueous sulfur concentrations close to those present in the reactor environment, but did not permit a proper evaluation of the various enviromental factors involved. This exphasizes the unique value of the CER test. Ho cracking occurred for the vater simulation of $1.37 \mathrm{H3BO}, 0.7 \mathrm{PP} S \mathrm{~S}$ (as $\mathrm{Ha}_{2} \mathrm{~S}_{2} \mathrm{O}_{3}$ ) and 0.7 Ppa Li (as LiOH) in a 4 week D-bend teat, whereas in an interrupted CER teat a 907 through-wall crack could be produced in 16 hours. For 1.37 H3203 with no lithiu hydroxide additions, cracking occurred at $Z 1.2$ ppe sulfur whether

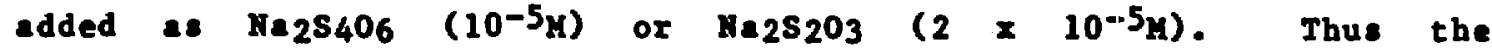
large effect of the chemical atate of sulfur is more noticable in the "leas sensitized" Mas aterial than in Sas naterial. 
Bven in the MAs material wost of the environmental effects observed in $\mathrm{D}-$ bend tests were exclusively associated with crack initiation. This was demonstrated by a composite experinent: a crack initiated by sow straining in 0.14 sodiu thiosulfate at $22^{\circ} \mathrm{C}$ continued to propagate at constant deflection for 2 daye in $1.37 \mathrm{H}_{3} \mathrm{BO}_{3}+0.7 \mathrm{ppa} \mathrm{s}$ (as Na25203). The cell was flushed repeatadly with the dilute olution. The average crack velocity following dilution was 1 n $a^{-1}$, and lithium hydroxide additions inhibited SCC as before, showing that the crack tip environment had altered to that characteristic of 0.7 ppa bulk sulfur concentration. Thus one does not need to invoke metallurgical variability to account for the failure of the whs teate to reproduce the steu generator cracking, provided that crack initiation was promoted in practice by some combination of factors not reproduced in the laboratory tests. Such factors include the secial nature of the sulfur-rich surface filw, which could locally generate aggressive metastable sulfur species such as polythionate ions.

\section{Conclusions}

1. Open-circuit CER testing in aqueous solutions may rank environments incorrectly owing to the influence of varying crack initiation statistice on the electrochemical potential of the specimen.

2. For sensitized Alloy 600 in dilute serated thiosulfate solutions, the variation of open-circuit potential during a CER teat is interpretable a an effect of currents energing from groving crack.

3. In this systen, measurenent of load relaxation following interruption of a CER teat is a very rapid way of investigating inbibiting additions to the colution. These additions often alter the rate of crack propagation reanrkably rapidly by influencing anion aigratinn into the cracks. 
4. Thioaulfate and tetrathionate ions, which cause similar rates of cracking in CER test, differ greatly in their ability to pronote smooth surface scC initiation. These effects vary with the metallurgical condition of the al1oy.

\section{Acknowledgemente}

This work was eponsored by the Nuclear Regulatory Commission under FIN No. A-3380. Discussions with D. D. MacDonald, J. R. Weeks and D. van Rooyen are gratefully acknowledged. Experimental asaistance was provided by Clifford Schnepf, Ronald Graeser and Kenneth Sutter. 


\section{References}

1. WRC final report on MMI-1 Task Group Investigation (in press).

2. R. C. Newman, R. Roberge \& R. Bandy, Corrosion (submitted 1982).

3. R. Bandy, R. Roberge 6 R. C. Newman, Corrosion (oubmitted 1982).

4. R. Sieradzki, H. S. Inasce \& R. C. Newman, papex no. 224, Corrosion 82, Houston, 1982. National Association of Corrosion Engineers, 1982.

5. J. C. Danko and S. W. Tagart, Jx.: Unpublished research, presented at Investigative Laboratory Reports on Stainlezs Steel Intergranular SCC in PWR Boric Acid Piping Syetem,, EPRI, Palo Alto, 1980.

6. R. C. Newman, R. Sieradzki and B. S. Isaace, Metall. Trans. (1982, in press).

7. H. S. Isaacs, B. Vyas t M. W. Kendig, Corrosion $\underline{38}, 130$ (1982).

8. R. C. Newman, R. Sieradzki \& B. S. Isaacs, Corrosion Science (1982, in press).

9. Ph. Berge \& J. R. Donati, Nuclear Technology $\underline{55}, 88$ (1981).

10. G. Cragnolino, S. Dhawale \& D. D MacDonald, EPRI Final Report, Project No. BP 1166-1 (1982).

11. R. L. Cowan and G. M. Gordon: Proc. Conf. "Stress-Corrosion Cracking and Bydrogen Drittlement of Iron Base Alloye", Firminy, 1973, p. 1023. MACE, Houston, 1977. 
Table 1 Analysis of Inconel 600 tubing

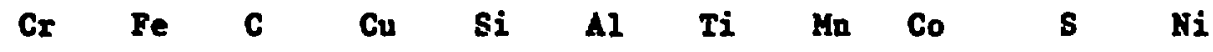

$\begin{array}{lllllllllllllll}\text { wt.7 } & 14.62 & 9.41 & 0.04 & 0.40 & 0.32 & 0.29 & 0.22 & 0.17 & 0.02 & 0.001 \text { balance }\end{array}$ 


\section{Eigure ceptions}

Firure 1 Microstructure of Inconel 600 tube material (electrolytic phosphoric acid etch)
(a) as received $+621^{\circ} \mathrm{C}$ for $18 \mathrm{~h}$
(b) $1135^{\circ} \mathrm{C}$ for $45 \mathrm{~min} .+621^{\circ} \mathrm{C}$ for $18 \mathrm{~h}$

Figure 2 Effect of lithium hydroxide addition on SCC of solution annealed/sensitized Inconel 600 in air saturated $1.37 \mathrm{H}_{3} \mathrm{BO}_{3}$ $+0.7 \mathrm{ppm}$ unlfur a $\mathrm{Na}_{2} \mathrm{~S}_{2} \mathrm{O}_{3}, 40^{\circ} \mathrm{C}$. Average crack velocity and elongation to failure are shown for CER terts at $3 \times$ $10^{-6},-1$ strain rate. For the interrupted CER test the crack velocity was estimated visually and from the linear load decay at constant deflection. Ductility loss is defined as ( $z$ elongation in air) - ( $\bar{z}$ elongation in environment).

Figure 3 Load variation following interruption of CER test of solution snnealed/sensitized Inconel 600 at $40^{\circ} \mathrm{C}$. Initisl solution was air saturated and contained $1.3 \% \mathrm{~B}_{3} \mathrm{BO}_{3}+0.7 \mathrm{ppm}$ sulfur as $\mathrm{Na}_{2} \mathrm{~S}_{2} \mathrm{O}_{3}$. Additions were made at times $A$ to $\mathrm{B}$, giving the compositions shown. The specimen contained one major crack. 
Figure 4 Load and potential variation during a CER teat of Inconel 600 , solution annealed and seneitized, in air-saturated 1.32 $\mathrm{H}_{3} \mathrm{BO}_{3}+7 \mathrm{ppm}$ sulfur as $\mathrm{Na}_{2} \mathrm{~S}_{2} \mathrm{O}_{3}+12 \mathrm{ppm} \mathrm{Li}$ as LiOH, $40^{\circ} \mathrm{C}$. Strain rate $-3 \times 10^{-6,-1}$. The extended elastic region is an artifact.
A: establishment of passive state
B: pre-initiation atage
C: several cracks initiated
D: several cracks in stage II growth giving constant polarizing current
E: polarizing current due to crack tip dissolutiou ceases at specimen failure.

Figure 5 Schematic illustration of the variation of steady-state specimen potential $(x, 0)$ with solution composition, crack velocity and number of cracks. Note that a CER test with $0.7 \mathrm{ppm} \mathrm{S}$ and no $\mathrm{Li}$ (many cracks) may give a lower mean cracking rate than a test with 2.1 ppu li added (one crack). 
Figure 1

(a)

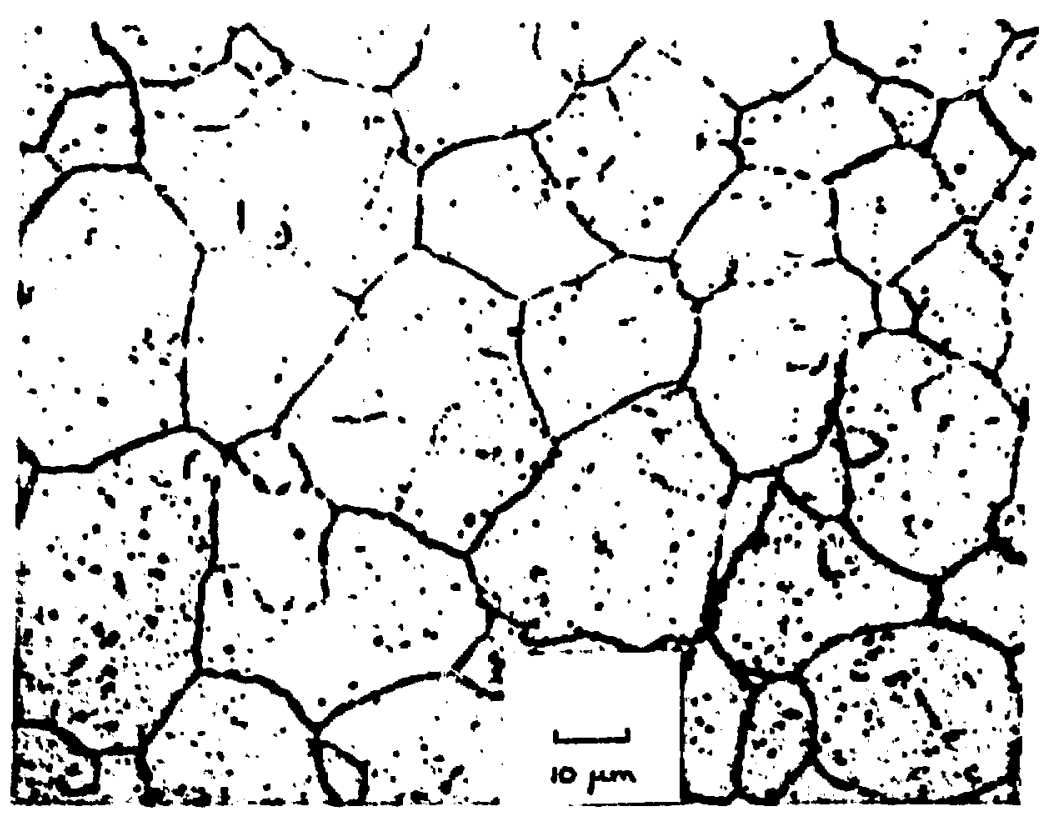

(b)

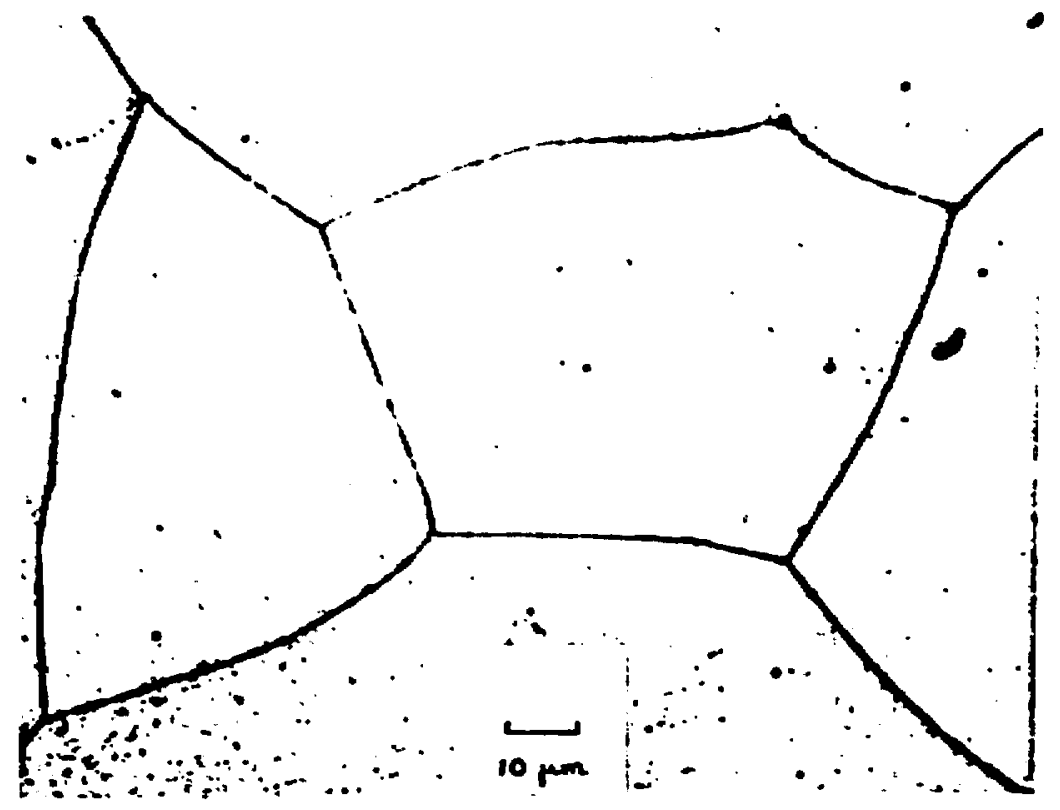




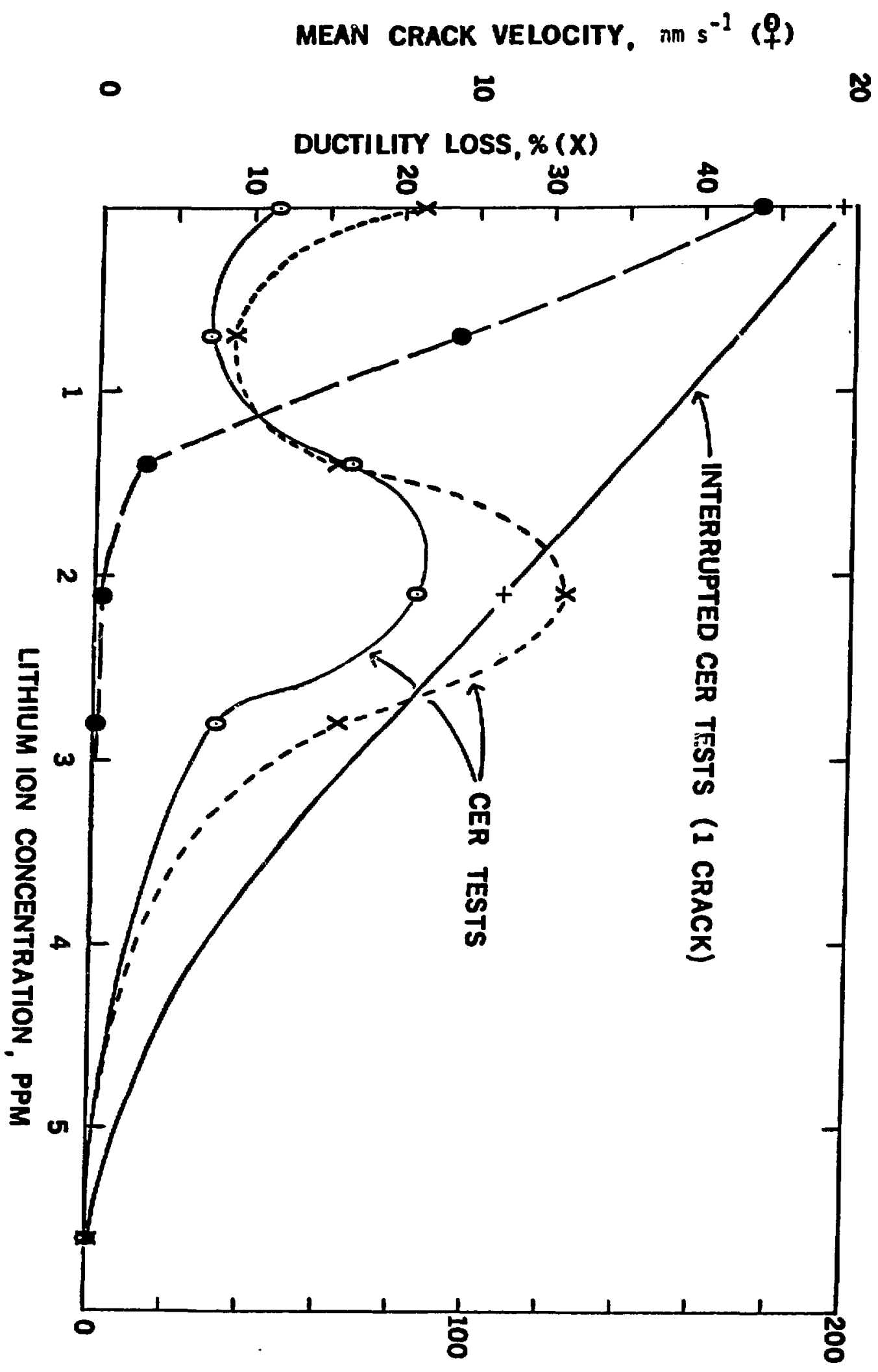

$\left.\right|_{\lambda} ^{\frac{\pi}{2}}$

(0) Sxovyo so yagwnN 


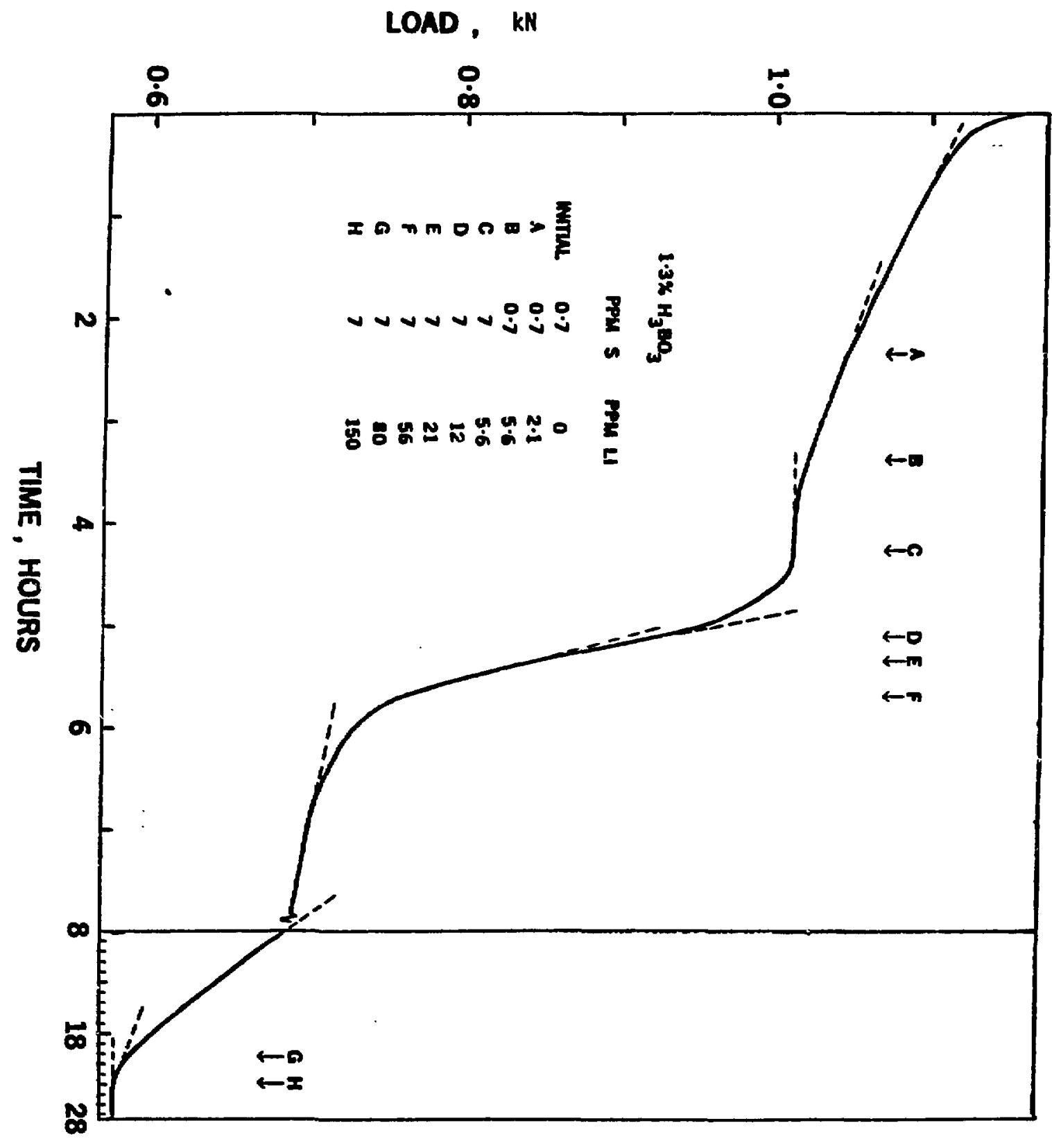


POTENTIAL, $V$ (SCE)

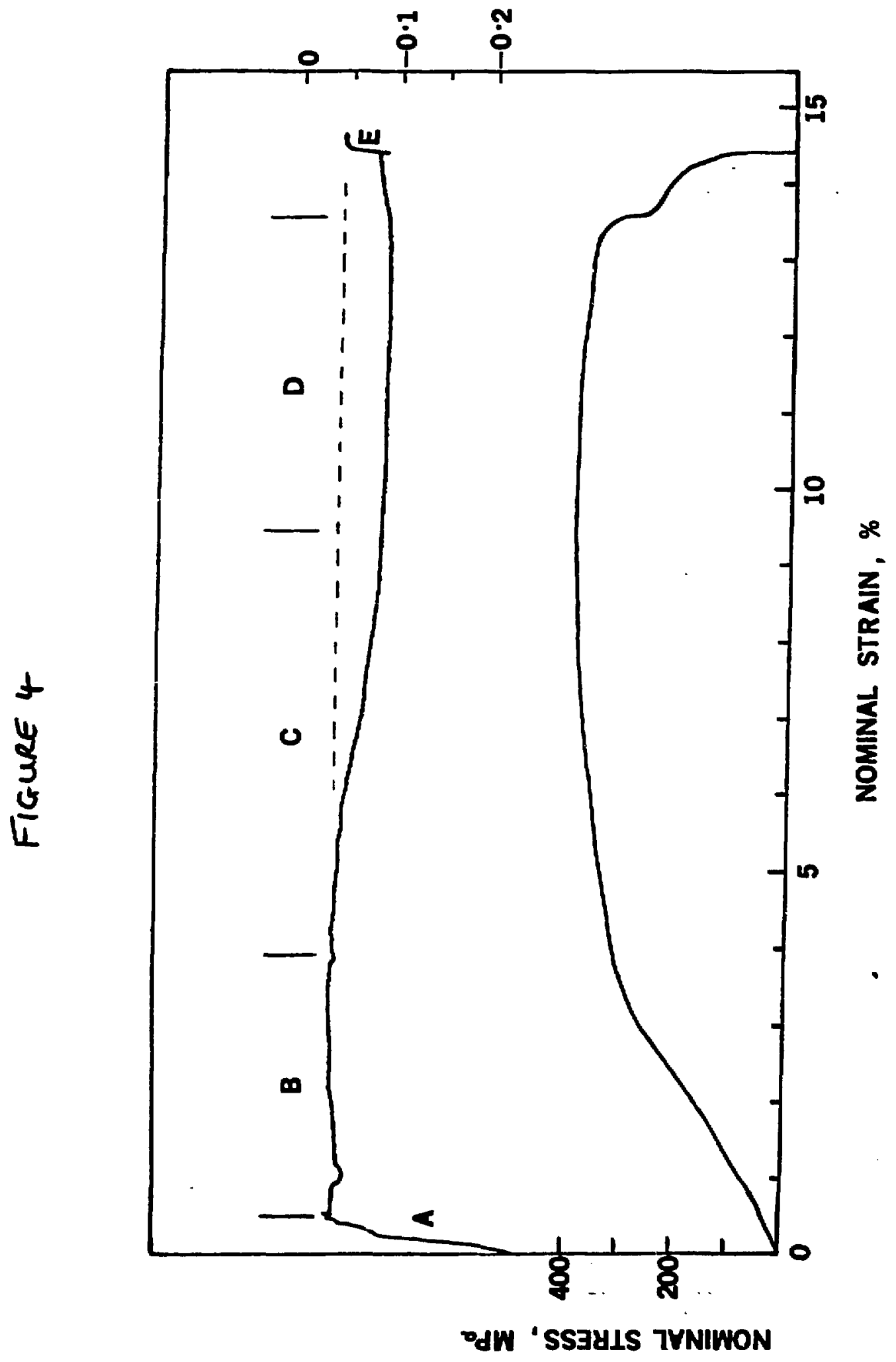


FIGURE 5

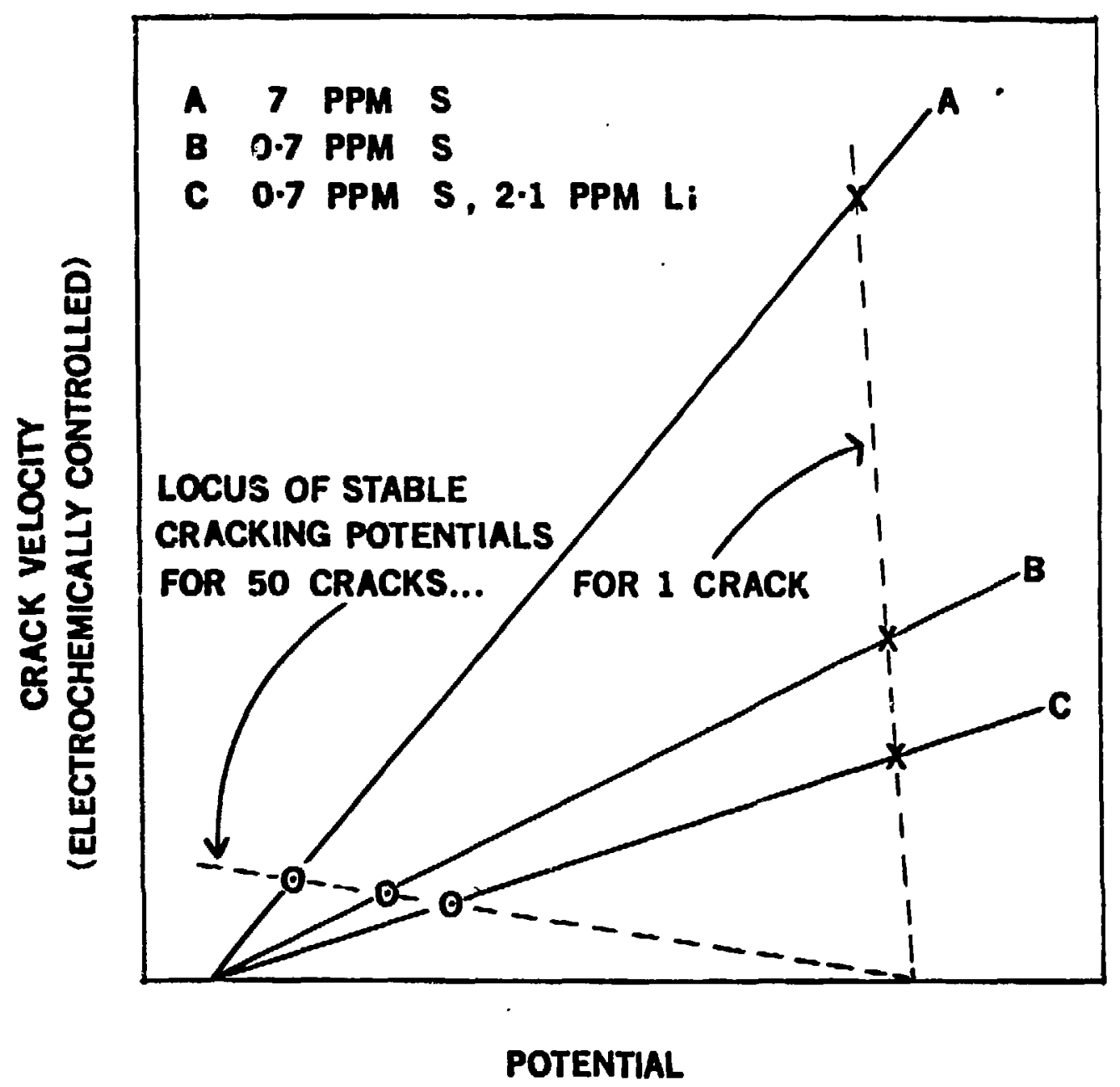

